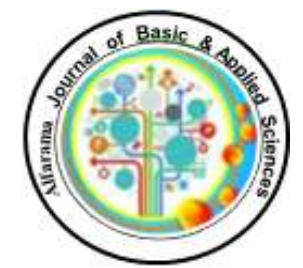

Alfarama Journal of Basic \& Applied Sciences

https://ajbas.journals.ekb.eg ajbas@sci.psu.edu.eg

Faculty of Science Port Said University

http://sci.psu.edu.eg/en/

July 2021, Volume 2, Issue 2

DOI: $10.21608 / A J B A S .2021 .63391 .1046$

ISSN 2682-275X

Submitted: $15 / 02 / 2021$

Accepted: 17 / $03 / 2021$

Pages: 181-193

\title{
Solvolysis Thermodynamic Parameters of Phenyl Hydrazine Hydrochloride
}

\author{
Noreldin S.Y. Abdalla ${ }^{1}$ and Farid I. El-Dossoki ${ }^{2^{*}}$ \\ ${ }^{1}$ Chemistry Department, Faculty of Science, Tobrouk University, Libya/Tobrouk and the current \\ address: Chemistry Department, University of Leicester, UK. University Road, Leicester LE1 7RH \\ ${ }^{2}$ Chemistry Department, Faculty of Science, Port-Said University, Port-Said, Egypt.
}

*Corresponding author: feldossoki64@ sci.psu.edu.eg

\begin{abstract}
The present work deals with studying the effect of solvent and temperature on the solvolysis process using both the $\mathrm{pH}$-metric and the conductometric measurements. The $\mathrm{pH}$ and the conductivity of different concentrations of the phenyl hydrazine hydrochloride in water $\left(\mathrm{H}_{2} \mathrm{O}\right)$, ethanol $(\mathrm{EtOH})$ and in $\left(\mathrm{EtOH}-\mathrm{H}_{2} \mathrm{O}\right)$ mixtures with different percentages of $\mathrm{EtOH} ; 30 \%, 50 \%, 70 \%, 100 \%$ (v/v) and at different temperatures from 293.15 to $308.15 \mathrm{~K}$ with a step of $5 \mathrm{~K}$ were measured experimentally. The conductivity of different concentrations of the phenyl hydrazine hydrochloride in aniline at the same temperatures was also measured. Depending on the measured $\mathrm{pH}$ and conductivity data, the solvolysis constant of phenyl hydrazine chloride was estimated. The thermodynamic parameters (free

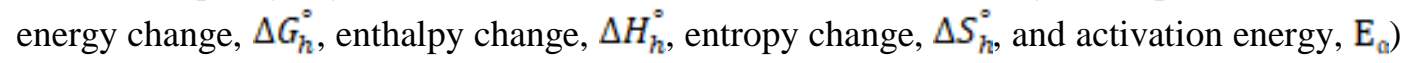
of the solvolysis process were evaluated from the temperature dependence of solvolysis constant. Positive values of the standard enthalpy change $\left(\Delta H_{h}^{\circ}\right)$, indicate that the solvolysis process is endothermic process. The solvolysis constant is increase as the alcohol percentage increase from $30 \%-100 \%$, which attributed to the higher solute-solvent interaction.
\end{abstract} Keywords:

Conductivity; pH-metric; Phenyl hydrazine hydrochloride; Solvolysis;

\section{INTRODUCTION}

Hydrolysis literally means reaction with water. It is a type of decomposition chemical reaction in which a molecule is used to break down the bonds of a particular substance. For all solvents; water and other solvents, it is preferred to use the expression; solvolysis. The first fragment of the parent molecule gains $\mathrm{H}^{+}$ion from the additional $\mathrm{H}_{2} \mathrm{O}$ molecule while the rest group collects the remaining $\mathrm{OH}$ group. In biotechnology and as far as living organisms are suffered about these types of substances which are often polymers $[1,2]$. Chemically, solvolysis is classified, into three main types which are salt, acid, and base hydrolysis. Hydrolysis occurs when a salt of a weak acid or weak base (or both) is dissolved in $\mathrm{H}_{2} \mathrm{O}$. 
Water auto ionizes into negative hydroxyl ions and hydrogen ions and the salt breaks down into (+) and (-) ions. This is the most common solvolysis process that can be occurred. In addition, solvolysis could also be thought of as the exact opposite reaction to condensation, which is the process by which two molecules combine to form one larger molecule. The end result of this reaction is that the larger molecule ejects a $\mathrm{H}_{2} \mathrm{O}$ molecule. Nonetheless, only a few reactions between $\mathrm{H}_{2} \mathrm{O}$ and organic compounds that can be occurred under normal conditions.[2,3] In general, strong acids or bases should be added in order to achieve solvolysis in which the water has no effect. The acid or base is considered a catalyst which making the reaction move faster, thereby increasing the reaction rate, but are recovered at the end of it.[3] Acid-base-catalyzed solvolysis are also common, one instance is the solvolysis of amides or esters. Their solvolysis happens when the nucleophile attacks the carbon of the carbonyl group of the amide or ester. In acid, the carbonyl group becomes protonated, and this leads to a much easier nucleophilic attack. Whilst, in an aqueous base, hydroxyl ions are better nucleophiles than dipoles such as water. In both hydrolyses processes (in acid and in aqueous base), the products are compounds with carboxylic acid groups. Salt solvolysis in water takes place by dissociation to form ions, either completely or incompletely this is depending on the respective solubility constant (Ksp). Perhaps one of the oldest examples: $\mathrm{NH}_{4} \mathrm{Br}_{(\mathrm{s})} \rightarrow$ $\mathrm{NH}_{4}+\mathrm{Br}$ the salt $\mathrm{NH}_{4} \mathrm{Br}$ in water dissociates into $\mathrm{NH}_{4}{ }^{+}$and $\mathrm{Br}^{-}$[4]. There are likely four mechanisms which can be forming the salts. In the first mechanism, salt is formed from a strong acid and weak base. In the second mechanism, salt is formed from a strong base and strong acid. In the third mechanism, salt is formed from a strong base and weak acid. In the last mechanism, salt can be formed from weak acid and a weak base. In all cases the solvolysis will take place and the acidity or basicity depends on the equilibrium constants $\mathrm{K}_{\mathrm{a}}$ and $\mathrm{K}_{\mathrm{b}}$. If the $\mathrm{K}_{\mathrm{a}}$ value is greater than the $\mathrm{K}_{\mathrm{b}}$ value, the resulting solution will be acidic and vice versa.[2, 3, 5] There are different factors can affect hydrolysis, include $\mathrm{pH}$, salt concentration, temperatures and solvolysis time which have been reported in detail.[4, 6-12] Several methods, including conductometric, $\mathrm{pH}$ titration,[5, 13, 14] spectrophotometry,[15-17] and ion-exclusion based chromatographic $[9,18]$ have been used to determine the hydrolytic rate of several compounds.[12, 17, 1921] As far as we know, the solvolysis rate of hydrazine and its derivatives have not been studied, especially for hydrazine hydrochloride salts.

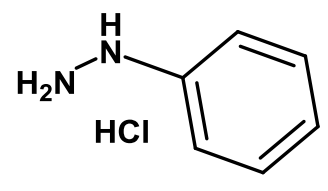

Structure 1: The Structure of Phenyl Hydrazine Hydrochloride

The objective for this paper was therefore to study the solvolysis of phenyl hydrazine hydrochloride (Structure 1), as an example of the salts of a weak base and strong acid, in water and alcoholic-water solvents at different temperatures $(293.15,298.15,303.15$, and $308.15 \mathrm{~K})$ by using two different techniques, including $\mathrm{pH}-\mathrm{metric}$ and conductometric measurements.

\section{EXPERIMENTAL}

\subsection{Materials and apparatus}

The chemicals utilized in this study are listed in Table 1. Bidistilled water with conductivity equal to $(2 \mu \mathrm{S} / \mathrm{cm})$ is used to prepare the solutions under study. The conductivity of the solutions under study was measured using the conductivity meter of type Jenway (4310) with measuring accuracy $( \pm 0.1 \mu \mathrm{S} / \mathrm{cm})$. The $\mathrm{pH}$ of the solutions was measured using the $\mathrm{pH}$-meter of type HI9813-6, with measuring accuracy 
$( \pm 0.1 \mathrm{pH}$ unit $)$ at different concentrations of Phenyl hydrazine hydrochloride with temperatures. The temperature of the solutions was adjusted to the selected temperature degree $\left( \pm 0.1{ }^{\circ} \mathrm{C}\right)$ using ultrathermostate water bath of type JSR JSWB-11T.

Table 1. List of chemicals used in this study

\begin{tabular}{|c|c|c|c|c|c|c|}
\hline chemical & CAS No. & suppliers & $\begin{array}{c}\text { Mass fraction } \\
\text { purity, }(\%)\end{array}$ & $\begin{array}{c}\text { purification } \\
\text { method }\end{array}$ & $\begin{array}{c}\text { boiling } \\
\text { Point, }{ }^{\circ} \mathrm{C}\end{array}$ & $\begin{array}{c}\mathrm{MW}, \\
\mathrm{g} \mathrm{mol}^{-1}\end{array}$ \\
\hline $\begin{array}{c}\text { Phenyl } \\
\text { hydrazine } \\
\text { hydrochloride, } \\
\mathrm{C}_{6} \mathrm{H}_{9} \mathrm{ClN}_{2} .\end{array}$ & 59-88-1 & $\begin{array}{c}\text { Santa Cruz } \\
\text { Biotechnology }\end{array}$ & $\geq 99.0 \%$ & none & $250-254$ & 44.60 \\
\hline $\begin{array}{c}\text { Ethanol, } \\
(\mathrm{EtOH}) \\
\mathrm{C}_{2} \mathrm{H}_{5} \mathrm{OH}\end{array}$ & $64-17-5$ & $\begin{array}{l}\text { Sigma-Aldrich } \\
\text { Company Ltd }\end{array}$ & $\begin{array}{l}\text { anhydrous, } \\
\geq 99.5\end{array}$ & none & 78 & 46.07 \\
\hline $\begin{array}{l}\text { Aniline, } \\
\mathrm{C}_{6} \mathrm{H}_{5} \mathrm{NH}_{2}\end{array}$ & $62-53-3$ & $\begin{array}{c}\text { Loba Chemie } \\
\text { Pvt Ltd }\end{array}$ & $\geq 99.0$ & none & 184 & 93.13 \\
\hline
\end{tabular}

\subsection{Procedure}

$0.002,0.005,0.01,0.015,0.02,0.025$ molar solutions of phenyl hydrazine hydrochloride were prepared in bidistilled water and aniline solvents. The $\mathrm{pH}$ of each solution in water at the selected temperature degree was measured. Also measure the conductivity of each solution in water and in aniline $\left(\kappa_{\mathrm{w}}\right.$ and $\kappa_{\mathrm{a}}$ respectively) at selected temperature degree.

\section{RESULTS AND DISSECTION}

\subsection{Estimating the solvolysis constant of phenyl hydrazine hydrochloride by using pH} measurements

The solvolysis of phenyl hydrazine hydrochloride as a salt of weak base and strong acid can be analyzed as follow: $\mathrm{C}_{6} \mathrm{H}_{5} \mathrm{NHNH}_{3} \mathrm{Cl}$ is made from acid $\mathrm{HCl}$ and base $\mathrm{C}_{6} \mathrm{H}_{5} \mathrm{NHNH}_{3} \mathrm{OH}$. In water $\mathrm{C}_{6} \mathrm{H}_{5} \mathrm{NHNH}_{3} \mathrm{Cl}$ dissociates completely in $\mathrm{C}_{6} \mathrm{H}_{5} \mathrm{NHNH}_{3}{ }^{+}$and $\mathrm{Cl}^{-}$ions. $\mathrm{C}_{6} \mathrm{H}_{5} \mathrm{NHNH}_{3}{ }^{+}$ions successfully polarize as follow:

$$
\begin{array}{ll}
\mathrm{C}_{6} \mathrm{H}_{5} \mathrm{NHNH}_{3} \mathrm{Cl}+\mathrm{H}_{2} \mathrm{O} \longrightarrow \mathrm{C}_{6} \mathrm{H}_{5} \mathrm{NHNH}_{3} \mathrm{OH}+\mathrm{HCl} \\
\mathrm{C}_{6} \mathrm{H}_{5} \mathrm{NHNH}_{3}{ }^{+}{ }_{(\mathrm{aq})}+\mathrm{H}_{2} \mathrm{O} \longrightarrow \mathrm{C}_{6} \mathrm{H}_{5} \mathrm{NHNH}_{3} \mathrm{OH}+\mathrm{H}^{+}
\end{array}
$$

$\mathrm{C}_{6} \mathrm{H}_{5} \mathrm{NHNH}_{3} \mathrm{OH}$ is a weak base which dissociates a little. Thus $\mathrm{OH}^{-}$ions of water are consumed by $\mathrm{C}_{6} \mathrm{H}_{5} \mathrm{NHNH}_{3}{ }^{+}$and $\mathrm{H}^{+}$reacts with $\mathrm{Cl}^{-}$ions. $\mathrm{Cl}^{-}+\mathrm{H}^{+} \leftrightarrow \mathrm{HCl}$; $\mathrm{HCl}$ is a strong acid and it dissociates completely. That means $\mathrm{H}^{+}$ions produced by solvolysis of $\mathrm{C}_{6} \mathrm{H}_{5} \mathrm{NHNH}_{3} \mathrm{Cl}$ salt remain in solution while $\mathrm{OH}^{-}$ions get trapped by $\mathrm{C}_{6} \mathrm{H}_{5} \mathrm{NHNH}_{3}{ }^{+}$. This higher concentration of $\mathrm{H}^{+}$ions makes the solution acidic.

\subsubsection{Quantitative Aspect of Hydrolysis.}

Solvolysis is a reversible reaction. The equilibrium constant derived by application of Law of mass action to a solvolysis (or hydrolytic) reaction is called the solvolysis constant or hydrolytic constant which is represented as $\mathrm{K}_{h}$. Now, we proceed to discuss the mathematics of solvolysis of the various types of salts, according to $\mathrm{pH}$ measurements. The solvolysis of a salt of a weak base $\mathrm{BOH}$ and a strong acid may be represented by the equation:

$$
\mathrm{B}^{+}+\mathrm{H}_{2} \mathrm{O} \leftrightarrow \mathrm{BOH}+\mathrm{H}^{+}
$$




\subsubsection{Solvolysis constant and the relation between $K_{h}, K_{w}$ and $K_{b}$}

Applying the Law of mass action to the above solvolysis reaction, the solvolysis constant, $K_{h}$, is given by: $K_{h}=\left[\mathrm{H}^{+}\right][\mathrm{BOH}] /\left[\mathrm{B}^{+}\right]\left[\mathrm{H}_{2} \mathrm{O}\right]$. Since $\left[\mathrm{H}_{2} \mathrm{O}\right]$ is very large, it is taken to be constant and the solvolysis constant expression is reduced to:

$$
\begin{gathered}
K_{h}=\left[\mathrm{H}^{+}\right][\mathrm{BOH}] /\left[\mathrm{B}^{+}\right] \\
K_{h}=\left[\mathrm{K}_{\mathrm{w}}\right] /\left[\mathrm{K}_{\mathrm{b}}\right]
\end{gathered}
$$

Thus the solvolysis constant $K_{h}$ varies inversely with the dissociation constant, $K_{b}$, of the base. Therefore, the weaker the base, the greater will be the solvolysis constant of the salt.

\subsubsection{The relation between $\mathrm{pH}$, concentration $(\mathrm{C})$ and $K_{h}$}

$$
\mathrm{pH}=-(1 / 2) \log \mathrm{K}_{\mathrm{h}}-(1 / 2) \log \mathrm{C}
$$

The value of $K_{h}$ was estimated by plotting $\mathrm{pH}$ vs. $\log \mathrm{C}$ which give a straight line with slope $=-(1 / 2)$ and intercept $=-(1 / 2) \log K_{h}$. The $\mathrm{pH}$ of different concentrations $(0.002,0.005,0.010,0.015,0.02,0.025 \mathrm{M})$ of Phenyl hydrazine hydrochloride in water at different temperature $(293.15,298.15,303.15$, and $308.15 \mathrm{~K})$ was measured and recorded in Table 2.

The $\mathrm{pH}$ values are increased with increasing of ethanol percentage in the mixture. This may be due to lower acidity of ethanol. Also, the $\mathrm{pH}$ values are decreased with rising of the $\mathrm{T}$ and concentration, which may be due to increase in the ionization process and libration of $\mathrm{H}^{+}$.

The solvolysis constant $K_{h}$ of phenyl hydrazine hydrochloride in $\mathrm{H}_{2} \mathrm{O}$ over the temperature range of (293.15 - $308.15 \mathrm{~K}$ ) was estimated according to equation $\mathbf{1 1}$ by plotting of $\mathrm{pH}$ versus $\log \mathrm{C}$ (Figure 1 as example), where the intercept equal $\left(-1 / 2 \log K_{h}\right)$. The values of the solvolysis constants $\left(K_{h}\right)$ were presented in Table 3.

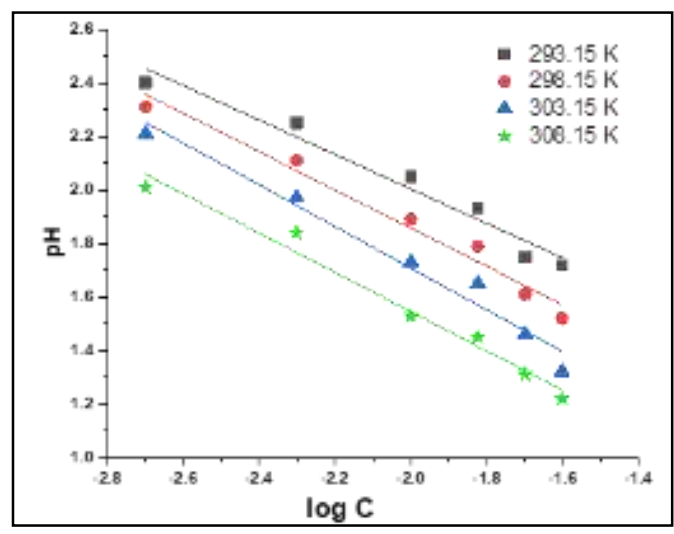

Figure 1. $\mathrm{pH}$ versus $\log \mathrm{C}$ for Phenyl hydrazine hydrochloride at different temperatures in $\mathrm{H}_{2} \mathrm{O}$

The free energy change of solvolysis $\left(\Delta G_{h}^{\circ}\right)$ was calculated at different temperatures by applying the following equation: 


$$
\Delta G_{h}^{\circ}=-2.303 \mathrm{RT} \log K_{h}
$$

Table 2. The $\mathrm{pH}$ of different concentrations of phenyl hydrazine hydrochloride in $\mathrm{H}_{2} \mathrm{O}$, EtOH and EtOH- $\mathrm{H}_{2} \mathrm{O}$ mixed solvents at different temperatures

\begin{tabular}{|c|c|c|c|c|c|c|c|c|}
\hline Conc. & \multicolumn{4}{|c|}{ pH in $0.0 \%$ EtOH } & \multicolumn{4}{|c|}{ pH in $30 \%$ EtOH } \\
\hline mol.l $l^{-1}$ & $\begin{array}{c}293.15 \\
\text { K }\end{array}$ & $\begin{array}{c}298.15 \\
\text { K }\end{array}$ & $\begin{array}{c}303.15 \\
\text { K }\end{array}$ & $\begin{array}{c}308.15 \\
\text { K }\end{array}$ & $\begin{array}{c}293.15 \\
\text { K }\end{array}$ & $\begin{array}{c}298.15 \\
\text { K }\end{array}$ & $\begin{array}{c}303.15 \\
\text { K }\end{array}$ & $\begin{array}{c}308.15 \\
\text { K }\end{array}$ \\
\hline 0.002 & 2.40 & 2.31 & 2.21 & 2.01 & 3.60 & 3.50 & 3.40 & 3.30 \\
\hline 0.005 & 2.25 & 2.11 & 1.97 & 1.84 & 3.05 & 3.00 & 2.95 & 2.90 \\
\hline 0.010 & 2.05 & 1.89 & 1.73 & 1.53 & 2.85 & 2.80 & 2.75 & 2.70 \\
\hline 0.015 & 1.93 & 1.79 & 1.65 & 1.45 & 2.77 & 2.70 & 2.62 & 2.40 \\
\hline 0.020 & 1.75 & 1.61 & 1.46 & 1.31 & 2.55 & 2.50 & 2.45 & 2.30 \\
\hline 0.025 & 1.72 & 1.52 & 1.32 & 1.22 & 2.50 & 2.40 & 2.30 & 2.20 \\
\hline$m o l . l^{-1}$ & \multicolumn{4}{|c|}{$\mathrm{pH}$ in $50 \%$ EtOH } & \multicolumn{4}{|c|}{$\mathrm{pH}$ in $70 \%$ EtOH } \\
\hline 0.002 & 3.90 & 3.80 & 3.70 & 3.60 & 4.15 & 4.0 & 3.85 & 3.70 \\
\hline 0.005 & 3.10 & 3.15 & 3.20 & 3.25 & 4.00 & 3.90 & 3.80 & 3.85 \\
\hline 0.010 & 2.60 & 2.65 & 2.70 & 2.75 & 3.80 & 3.75 & 3.70 & 3.50 \\
\hline 0.015 & 2.50 & 2.55 & 2.60 & 2.65 & 3.50 & 3.30 & 3.10 & 2.90 \\
\hline 0.020 & 2.30 & 2.35 & 2.40 & 2.45 & 3.10 & 2.95 & 2.89 & 2.50 \\
\hline 0.025 & 2.20 & 2.25 & 2.30 & 2.35 & 2.80 & 2.70 & 2.60 & 2.40 \\
\hline \multirow{2}{*}{ mol. $l^{-1}$} & \multicolumn{8}{|c|}{ pH in $100 \%$ EtOH } \\
\hline & \multicolumn{2}{|c|}{$293.15 \mathrm{~K}$} & \multicolumn{2}{|c|}{$298.15 \mathrm{~K}$} & \multicolumn{2}{|c|}{$303.15 \mathrm{~K}$} & \multicolumn{2}{|c|}{$308.15 \mathrm{~K}$} \\
\hline 0.002 & \multicolumn{2}{|c|}{3.20} & \multicolumn{2}{|c|}{3.10} & \multicolumn{2}{|c|}{3.00} & \multicolumn{2}{|c|}{2.90} \\
\hline 0.005 & \multicolumn{2}{|c|}{2.90} & \multicolumn{2}{|c|}{2.80} & \multicolumn{2}{|c|}{2.70} & \multicolumn{2}{|c|}{2.60} \\
\hline 0.010 & \multicolumn{2}{|c|}{2.65} & \multicolumn{2}{|c|}{2.50} & \multicolumn{2}{|c|}{2.40} & \multicolumn{2}{|c|}{2.30} \\
\hline 0.015 & \multicolumn{2}{|c|}{2.40} & \multicolumn{2}{|c|}{2.30} & \multicolumn{2}{|c|}{2.20} & \multicolumn{2}{|c|}{2.10} \\
\hline 0.020 & \multicolumn{2}{|c|}{2.20} & \multicolumn{2}{|c|}{2.10} & \multicolumn{2}{|c|}{2.00} & \multicolumn{2}{|c|}{1.90} \\
\hline 0.025 & \multicolumn{2}{|c|}{2.10} & \multicolumn{2}{|c|}{2.00} & \multicolumn{2}{|c|}{1.90} & & \\
\hline
\end{tabular}

The enthalpy change $\left(\Delta H_{h}^{\circ}\right)$ and the entropy change $\left(\Delta S_{h}^{\infty}\right)$ of solvolysis applying the following equation by plotting $\left(\Delta G_{h}^{\infty}\right)$, versus (T) (Figure 2a, as example) where the intercept is $\left(\Delta H_{h}^{\circ}\right)$ and the slope is $\left(-\Delta S_{h}^{\circ}\right)$,

The activation energy of

$$
\Delta G_{h}^{\circ}=\Delta H_{h}^{\circ}-\mathrm{T}\left(\Delta S_{h}^{\circ}\right)
$$

the solvolysis process $\left(K_{h}\right)$ was calculated by applying Arrhenius equation where the solvolysis process depending on temperature degree as follow:

$$
\mathrm{K}_{h}=\mathrm{A} \mathrm{e} \mathrm{e}^{(-\mathrm{Ea} / \mathrm{RT})}
$$

Plotting of $\left(\ln K_{h}\right)$ versus $(1 / \mathrm{T})$, gives straight line with slope equal (-Ea/R), where $\mathrm{R}$ is the universal gas constant $\left(8.314 \mathrm{~J} / \mathrm{K} \mathrm{mol}\right.$ ) (Figure $\mathbf{2 b}$, as an example). The values of the solvolysis constant $K_{h}$, the free energy change $\left(\Delta G_{h}^{\circ}\right)$, enthalpy change $\left(\Delta H_{h}^{\circ}\right)$, the entropy change $\left(\Delta S_{h}^{\circ}\right)$ and the activation energy $\left(\boldsymbol{E}_{a}\right)$ of the solvolysis process are summarized in Tables 3. According to the results obtained, the $K_{h}$ is greatly 
influenced by both temperature and solvent compositions. Increasing the temperature degree, lead to significant increases in the solvolysis reaction rate of phenyl hydrazine hydrochloride. This can be related to increase in the ionization process and libration of hydrogen ion as the temperature degree increase. This was subsequently confirmed by the positive values of the free energy change and the activation energy of the solvolysis process.[12, 17, 19-22] The positive values of the free energy change $\left(\Delta G_{k}^{\circ}\right)$ and the standard enthalpy change $\left(\Delta H_{h}^{\circ}\right)$, indicate that the solvolysis process is non spontaneous endothermic process.[12, 17, 19-21]. The solvolysis constant is increase as the alcohol percentage increase from 30$100 \%$. This may be due to the higher solute-solvent interaction.[12, 17, 19-21]

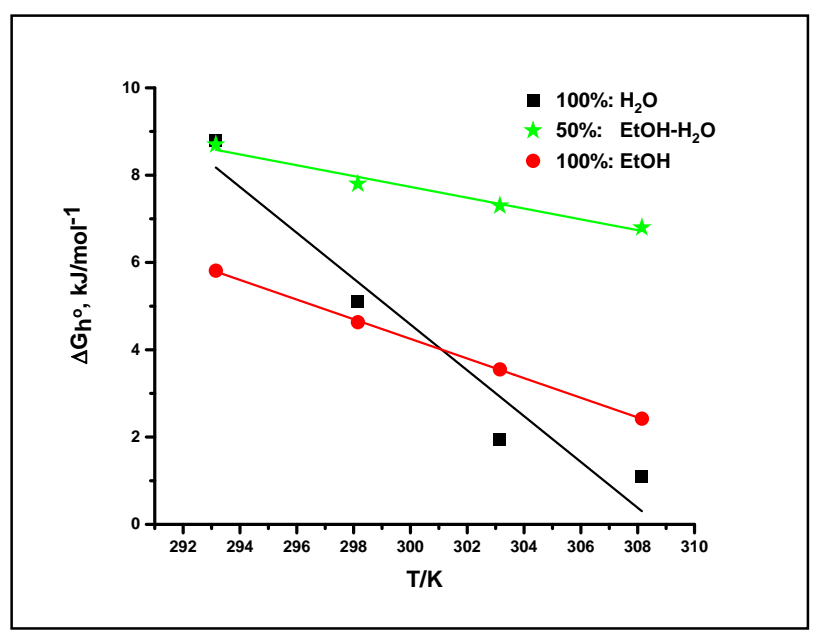

(a)

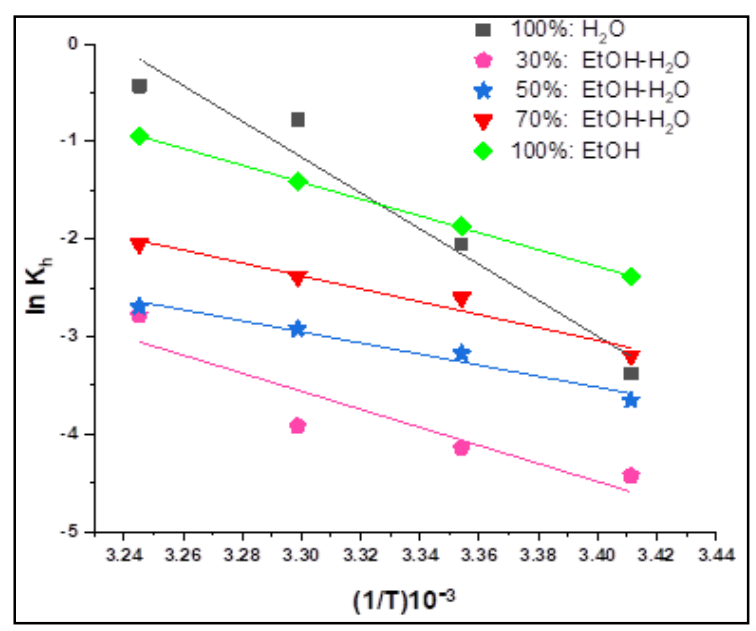

(b)

Figure 2. (a). The temperature dependence of $\left(\Delta G_{h}^{\circ}\right)$, for phenyl hydrazine hydrochloride in different solvents; (b). Relation of $\ln \ln K_{h} v s$. (1/T) for phenyl hydrazine hydrochloride in different solvents.

\subsection{Estimation of solvolysis constant of phenyl hydrazine hydrochloride using conductometric measurements.}

According to the conductometric measurements, the solvolysis constant of the salt can be determined as in the following manner: The Phenyl hydrazine hydrochloride solvolysis in the following manner liberating free acid:

$$
\underset{(1-\alpha) \mathrm{C}}{\mathrm{C}_{6} \mathrm{H}_{5} \mathrm{NHNH}_{3}{ }^{+} \mathrm{Cl}^{-}+\mathrm{H}_{2} \mathrm{O} \longrightarrow \underset{\alpha}{\mathrm{C}_{6} \mathrm{H}_{5} \mathrm{NHNH}_{3} \mathrm{OH}+\mathrm{H}^{+} \mathrm{Cl}^{-}}} \underset{\alpha \mathrm{C}}{ }
$$

The solvolysis constant $K_{h}$ is given by:

$$
K_{h}=\alpha \mathrm{C} \alpha \mathrm{C} /(1-\alpha) \mathrm{C}=\alpha^{2} \mathrm{C}
$$

Where $\alpha$ is the degree of solvolysis and $\mathrm{C}$ is the concentration of Phenyl hydrazine hydrochloride salt in $\mathrm{mol} / \mathrm{L}$. The molar conductance of a solution of phenyl hydrazine hydrochloride is related to the concentration and the $K_{h}$, as follow:

From equation $15, \quad K_{h}=\alpha^{2} \mathrm{C} ; \quad \alpha=\left(\Lambda_{w}-\Lambda_{a}\right) /\left(\Lambda_{0}-\Lambda_{a}\right)$

Where; $\Lambda_{\circ}$ is the limiting molar conductance of $\mathrm{HCl}$ in an aqueous solution at $25^{\circ} \mathrm{C}=426.16 \mathrm{~S} \mathrm{~cm}^{2} \mathrm{~mol}^{-1}$. 


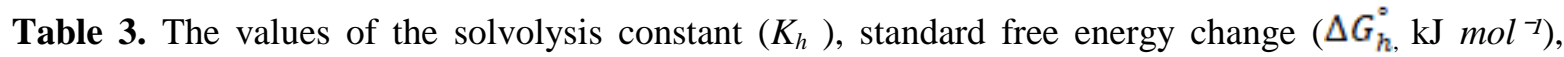
standard enthalpy change $\left(\Delta H_{k}^{\circ}, \mathrm{kJ} \mathrm{mol}^{-1}\right)$, standard entropy change $\left(\Delta S_{h}^{\circ} \mathrm{kJ} m \mathrm{~m}^{-1} \mathrm{~K}\right)$ and the activation energy $\left(E_{a}, \mathrm{~kJ} \mathrm{~mol}^{-1}\right)$ of the solvolysis process of phenyl hydrazine hydrochloride at different temperature in the solvent used, derived from $\mathrm{pH}$ measurements

\begin{tabular}{|c|c|c|c|c|c|c|}
\hline Solvent & $\mathbf{T} / \mathbf{K}$ & $K_{h}$ & $\Delta G_{h}^{\prime \prime}$ & $\Delta H_{h}^{2}$ & $\Delta S_{h}^{g}$ & $E_{a}$ \\
\hline \multirow{4}{*}{$0.0 \%$ EtOH } & 293.15 & 0.034 & 8.80 & \multirow{4}{*}{162} & \multirow{4}{*}{0.525} & \multirow{4}{*}{0.155} \\
\hline & 298.15 & 0.128 & 5.10 & & & \\
\hline & 303.15 & 0.460 & 1.95 & & & \\
\hline & 308.15 & 0.650 & 1.10 & & & \\
\hline \multirow{4}{*}{ 30\% EtOH } & 293.15 & 0.012 & 10.78 & \multirow{4}{*}{77.870} & \multirow{4}{*}{0.227} & \multirow{4}{*}{0.042} \\
\hline & 298.15 & 0.016 & 10.25 & & & \\
\hline & 303.15 & 0.020 & 9.86 & & & \\
\hline & 308.15 & 0.062 & 7.12 & & & \\
\hline \multirow{4}{*}{$50 \%$ EtOH } & 293.15 & 0.026 & 8.70 & \multirow{4}{*}{44.912} & \multirow{4}{*}{0.124} & \multirow{4}{*}{0.046} \\
\hline & 298.15 & 0.042 & 7.80 & & & \\
\hline & 303.15 & 0.054 & 7.30 & & & \\
\hline & 308.15 & 0.068 & 6.80 & & & \\
\hline \multirow{4}{*}{$70 \%$ ЕtOH } & 293.15 & 0.041 & 7.78 & \multirow{4}{*}{54.835} & \multirow{4}{*}{0.161} & \multirow{4}{*}{0.054} \\
\hline & 298.15 & 0.074 & 6.45 & & & \\
\hline & 303.15 & 0.092 & 6.01 & & & \\
\hline & 308.15 & 0.129 & 5.24 & & & \\
\hline \multirow{4}{*}{$100 \%$ EtOH } & 293.15 & 0.092 & 5.81 & \multirow{4}{*}{71.767} & \multirow{4}{*}{0.225} & \multirow{4}{*}{0.071} \\
\hline & 298.15 & 0.154 & 4.63 & & & \\
\hline & 303.15 & 0.244 & 3.55 & & & \\
\hline & 308.15 & 0.389 & 2.42 & & & \\
\hline
\end{tabular}

$\Lambda_{w}$ is the molar conductance of Phenyl hydrazine hydrochloride of molar concentration, $\mathrm{C}$ in aqueous solution at $298 \mathrm{~K} . \Lambda_{a}$ is the molar conductance of Phenyl hydrazine hydrochloride of molar concentration, $\mathrm{C}$ in aniline solution at $298 \mathrm{~K}$. In aniline solution it supposes that the phenyl hydrazine hydrochloride is unhydrolysed and remain in the molecular state. It follows that the conductivity due to the resulted $\mathrm{HCl}$ from one g equivalent of phenyl hydrazine hydrochloride in an aqueous solution of molar concentration, $\mathrm{C}$ is $\left(\alpha \Lambda_{\circ}\right)$ while the conductivity due to one $\mathrm{g}$ equivalent of the unhydrolysed phenyl hydrazine hydrochloride in aqueous solution of molar concentration, $\mathrm{C}$ is $\left\{(1-\alpha) \Lambda_{a}\right\}$, then

$$
\begin{gathered}
\left.\Lambda_{w}=\left(\alpha \Lambda_{\circ}\right)+\{1-\alpha) \Lambda_{a}\right\} \\
=\alpha \Lambda_{\circ}+\Lambda_{a}-\alpha \Lambda_{a} \\
\Lambda_{w}-\Lambda_{a}=\alpha \Lambda_{o}-\alpha \Lambda_{a} \\
\Lambda_{w}-\Lambda_{a}=\alpha\left(\Lambda_{\circ}-\Lambda_{a}\right) \\
\alpha=\left(\Lambda_{w}-\Lambda_{a}\right) \operatorname{V} /\left(\Lambda_{o}-\Lambda_{a}\right)
\end{gathered}
$$

The value of the solvolysis constant $K_{h}$ can be calculated directly from; 


$$
\alpha=\left(\Lambda_{w}-\Lambda_{a}\right) /\left(\Lambda_{\circ}-\Lambda_{a}\right) K_{h}=\alpha^{2} \mathrm{C}
$$

Also, the value of the solvolysis constant $K_{h}$ can be calculated applying the following equation:

$$
\text { or } \quad 2 \log \alpha=\log K_{h}-\log \mathrm{C}
$$

Draw the relation between $\log \mathrm{C}$ and $\log \alpha$ to obtain the value of $K_{h}$ from the intercept. The value of $\Lambda_{w}$ and $\Lambda_{a}$ can be calculated by using the following equation:

$$
\begin{gathered}
\Lambda_{w}=1000 \kappa_{u} / \mathrm{C} \text { in water where } \\
\Lambda_{a}=1000 \kappa_{a} / \mathrm{C} \text { in aniline where }
\end{gathered}
$$

Where $\left(\kappa_{w}\right.$ and $\left.\kappa_{a}\right)$ are the conductivity of Phenyl hydrazine hydrochloride in water and in aniline respectively which measured using a conductivity cell. The conductivity of different concentrations $(0.002,0.005,0.010,0.015,0.02,0.025 \mathrm{M})$ of Phenyl hydrazine hydrochloride in water and in aniline at different temperature $(293.15,298.15,303.15$, and $308.15 \mathrm{~K})$ was measured and recorded in Table 4.

According to the results listed in Table 4 the value of the conductivity of phenyl hydrazine hydrochloride in aniline is very lower than that in either $\mathrm{H}_{2} \mathrm{O}$ or the EtOH- $\mathrm{H}_{2} \mathrm{O}$ mixture over the all temperatures range used. This can be mainly attributed to no solvolysis of phenyl hydrazine hydrochloride in aniline. $\kappa_{\mathrm{a}}$ values are almost equal for each concentration of phenyl hydrazine hydrochloride at the same $\mathrm{T}$, while these values are increased with increasing of the temperatures. This is as a result of in aniline solution it supposes that the phenyl hydrazine hydrochloride is unhydrolysed and remain in the molecular state. As the $\mathrm{T}$ increase the hydrolysis of phenyl hydrazine hydrochloride may increase and so the conductivity, $\kappa_{\mathrm{a}}$ increases. The solvolysis constant of Phenyl hydrazine hydrochloride was calculated according to equation $\mathbf{1 3}$ by plotting $\log \alpha$ versus $\log \mathrm{C}$ (Figure 3).

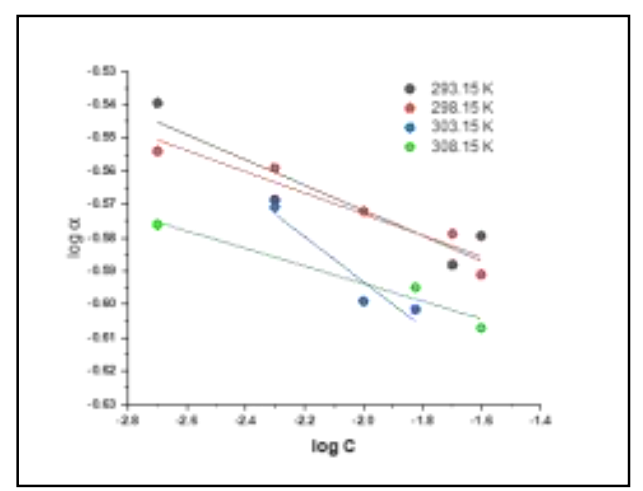

Figure 3. $\log (\mathrm{C}) v s \cdot \log (\alpha)$ for Phenyl hydrazine hydrochloride in $\mathrm{H}_{2} \mathrm{O}$ at different temperatures

The free energy change $\left(\Delta G_{h}^{\circ}\right)$, the enthalpy change $\left(\Delta H_{h}^{\circ}\right)$, the entropy change $\left(\Delta S_{k}^{\circ}\right)$ and the activation energy $\left(\boldsymbol{E}_{\boldsymbol{a}}\right)$ of the solvolysis process of phenyl hydrazine hydrochloride were calculated as explained in the $\mathrm{pH}$ measurements according to equations 13-15. Figure 4a, show the relation between $\left(\Delta G_{h}^{\circ}\right)$, and $(\mathrm{T})$ for estimation of $\left(\Delta H_{h}^{\circ}\right.$ and $\left.\Delta S_{h}^{\circ}\right)$, Figure $4 \mathbf{b}$, show the relation of $\ln K_{h} v s .(1 / \mathrm{T})$ for calculation of the activation energy of the solvolysis process. 
Table 4. The conductivity $(\mu \mathrm{S} / \mathrm{cm})$ of different concentrations of phenyl hydrazine hydrochloride in water $\left(\kappa_{w}\right)$ and in aniline $\left(\kappa_{a}\right)$ at different temperatures

\begin{tabular}{|c|c|c|c|c|c|c|c|c|}
\hline \multirow{3}{*}{$\begin{array}{l}\text { Conc. } \\
\mathrm{mol} \mathrm{l}^{-1}\end{array}$} & \multicolumn{8}{|c|}{$0.0 \%$ EtOH } \\
\hline & \multicolumn{2}{|c|}{$293.15 \mathrm{~K}$} & \multicolumn{2}{|c|}{298.15 K } & \multicolumn{2}{|c|}{$303.15 \mathrm{~K}$} & \multicolumn{2}{|c|}{$308.15 \mathrm{~K}$} \\
\hline & $\kappa_{w}$ & $\kappa_{a}$ & $\kappa_{w}$ & $\kappa_{a}$ & $\kappa_{w}$ & $\kappa_{a}$ & $\kappa_{w}$ & $\kappa_{a}$ \\
\hline$m o l l^{-1}$ & \multicolumn{8}{|c|}{$0.0 \%$ EtOH } \\
\hline 0.002 & 228.00 & 0.710 & 237 & 0.70 & 245.80 & 0.690 & 254.9 & 0.690 \\
\hline 0.005 & 532.50 & 0.820 & 585 & 0.99 & 637.46 & 1.150 & 689.9 & 1.320 \\
\hline 0.010 & 1135.5 & 1.775 & 1137 & 2.38 & 1138.45 & 2.585 & 1139.9 & 2.790 \\
\hline 0.015 & 1489.5 & 4.175 & 1603 & 4.37 & 1716.50 & 4.565 & 1829.9 & 4.760 \\
\hline 0.020 & 2038.0 & 4.360 & 2241 & 4.55 & 2443.90 & 4.740 & 2646.9 & 4.930 \\
\hline 0.025 & 2598.0 & 3.580 & 2721 & 4.70 & 2843.90 & 5.820 & 2966.9 & 6.930 \\
\hline $\mathrm{mol} \mathrm{l}^{-1}$ & \multicolumn{8}{|c|}{$30 \%$ EtOH } \\
\hline 0.002 & 220 & 0.710 & 251 & 0.70 & 280 & 0.690 & 308 & 0.690 \\
\hline 0.005 & 550 & 0.820 & 583 & 0.99 & 610 & 1.150 & 640 & 1.320 \\
\hline 0.010 & 960 & 1.775 & 1060 & 2.38 & 1160 & 2.585 & 1250 & 2.790 \\
\hline 0.015 & 1270 & 4.175 & 1390 & 4.37 & 1500 & 4.565 & 1620 & 4.760 \\
\hline 0.020 & 1507 & 4.360 & 1590 & 4.55 & 1680 & 4.740 & 1770 & 4.930 \\
\hline 0.025 & 1750 & 3.580 & 1887 & 4.70 & 1740 & 5.820 & 2140 & 6.930 \\
\hline$m o l l^{-1}$ & \multicolumn{8}{|c|}{$50 \%$ EtOH } \\
\hline 0.002 & 266 & 0.002 & 266 & 0.002 & 266 & 0.002 & 266 & 0.002 \\
\hline 0.005 & 420 & 0.820 & 460 & 0.99 & 510 & 1.150 & 577 & 1.320 \\
\hline 0.010 & 695 & 1.775 & 813 & 2.38 & 898 & 2.585 & 953 & 2.790 \\
\hline 0.015 & 953 & 4.175 & 1115 & 4.37 & 1560 & 4.565 & 1252 & 4.760 \\
\hline 0.020 & 1109 & 4.360 & 1290 & 4.55 & 1398 & 4.740 & 1496 & 4.930 \\
\hline 0.025 & 1200 & 3.580 & 1398 & 4.70 & 1519 & 5.820 & 1798 & 6.930 \\
\hline$m o l l^{-1}$ & \multicolumn{8}{|c|}{ 70\% ЕtOH } \\
\hline 0.002 & 48 & 0.710 & 51 & 0.70 & 55 & 0.690 & 58 & 0.690 \\
\hline 0.005 & 103 & 0.820 & 119 & 0.99 & 135 & 1.150 & 150 & 1.320 \\
\hline 0.010 & 204 & 1.775 & 221 & 2.38 & 243 & 2.585 & 265 & 2.790 \\
\hline 0.015 & 336 & 4.175 & 370 & 4.37 & 404 & 4.565 & 435 & 4.760 \\
\hline 0.020 & 421 & 4.360 & 470 & 4.55 & 519 & 4.740 & 567 & 4.930 \\
\hline 0.025 & 496 & 3.580 & 551 & 4.70 & 606 & 5.820 & 661 & 6.930 \\
\hline $\mathrm{mol} \mathrm{l}^{-1}$ & \multicolumn{8}{|c|}{$100 \%$ EtOH } \\
\hline 0.002 & 19.77 & 0.710 & 21.48 & 0.70 & 23.19 & 0.690 & 58 & 0.690 \\
\hline 0.005 & 58.37 & 0.820 & 63.08 & 0.99 & 67.79 & 1.150 & 150 & 1.320 \\
\hline 0.010 & 124.67 & 1.775 & 134.48 & 2.38 & 144.29 & 2.585 & 265 & 2.790 \\
\hline 0.015 & 192.37 & 4.175 & 206.78 & 4.37 & 221.19 & 4.565 & 435 & 4.760 \\
\hline 0.020 & 231.37 & 4.360 & 251.78 & 4.55 & 272.19 & 4.740 & 567 & 4.930 \\
\hline 0.025 & 289.37 & 3.580 & 313.78 & 4.70 & 338.19 & 5.820 & 661 & 6.930 \\
\hline
\end{tabular}




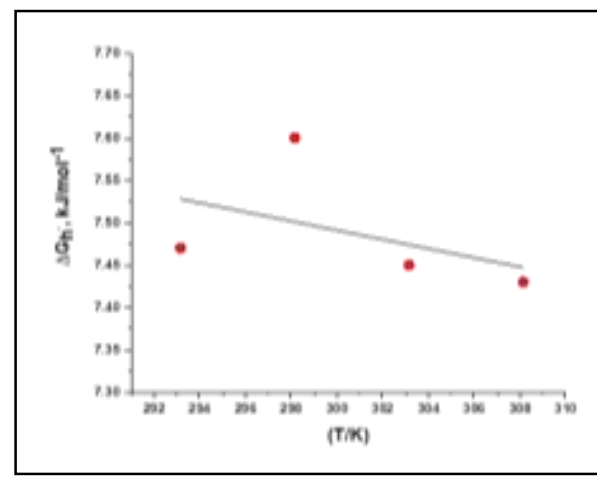

(a)

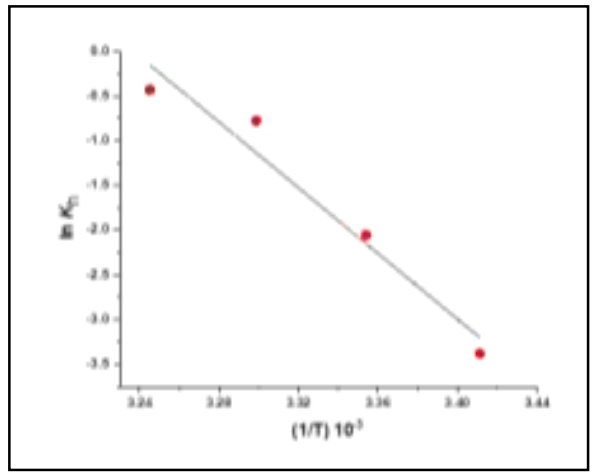

(b)

Figure 4. (a): The temperature dependence of $\left(\Delta G_{k}^{\circ}\right)$, for Phenyl hydrazine hydrochloride at different solvents; (b): Relation of $\ln K_{h} v s$. (1/T) for Phenyl hydrazine hydrochloride in $\mathrm{H}_{2} \mathrm{O}$

The values of the solvolysis constant $\left(K_{h}\right)$, free energy change $\left(\Delta G_{h}^{\circ}\right)$, enthalpy change $\left(\Delta H_{h}^{\circ}\right)$, entropy change $\left(\Delta S_{h}^{\circ}\right)$, and the activation energy $\left(\boldsymbol{E}_{a}\right)$, of the solvolysis process of phenyl hydrazine hydrochloride are listed in Table 5. The results listed in Table 5 indicated that the solvolysis constant increase as the temperature degree increase as subsequently confirmed by the positive values of the free energy change $\left(\Delta G_{k}^{\circ}\right)$, and the activation energy of the solvolysis process.[12, 17, 19-21] The positive values of the free energy change $\left(\Delta G_{h}^{\circ}\right)$ and the standard enthalpy change $\left(\Delta H_{h}^{\circ}\right)$, indicate that the solvolysis process is non spontaneous endothermic process.[12, 17, 19-21] The solvolysis constant decrease as the ethanol added to water. This may be due to the lower dielectric constant and lower dipole moment of EtOH- $\mathrm{H}_{2} \mathrm{O}$ mixed solvent than that of $\mathrm{H}_{2} \mathrm{O}$. On the other hand, the effect of ethanol percentage is not as expected. It was observed that the solvolysis constant values increase with increasing the EtOH percentage from 30 to $100 \%$. This may be due to the higher solute-solvent interaction.[19\&20]

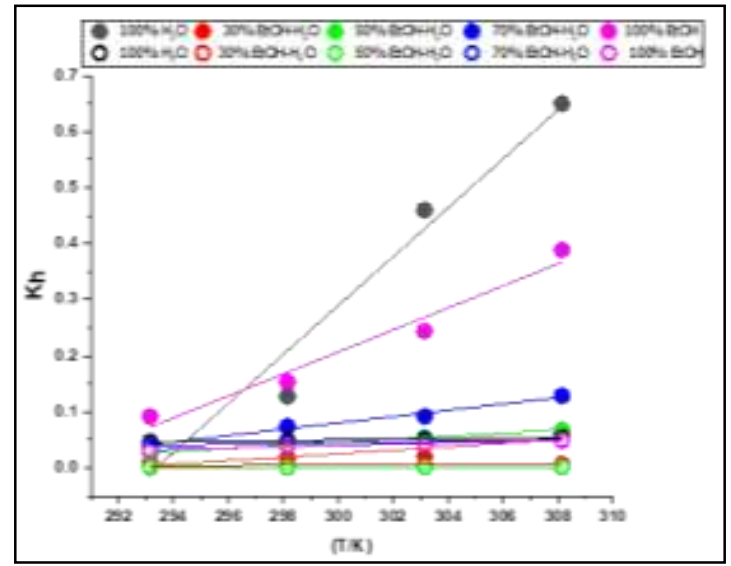

Figure 5. Comparison of the solvolysis constant $\mathrm{Kh}$ values for of phenyl hydrazine hydrochloride using the $\mathrm{pH}$ measurement $(O)$ and the conductivity measurement (5). 
Table 5. The values of the solvolysis constant $\left(K_{h}\right)$, standard free energy change $\left(\Delta G_{h}^{\circ}, \mathrm{kJ}^{2} \mathrm{lol}^{-1}\right)$, standard enthalpy change $\left(\Delta H_{k}^{\infty}, \mathrm{kJ} \mathrm{mol}^{-1}\right)$, standard entropy change $\left(\Delta S_{k}^{\infty} \mathrm{KJ} \mathrm{mol}^{-1} . \mathrm{K}\right)$ and the activation energy $\left(\mathrm{E}_{\text {⿷匚 }}, \mathrm{kJ} \mathrm{mol}^{-1}\right)$ of the solvolysis process of phenyl hydrazine hydrochloride, derived from conductometric measurements.

\begin{tabular}{|c|c|c|c|c|c|c|}
\hline Solvent & $T / K$ & $\overline{K_{h}}$ & $\Delta G_{h}^{\circ}$ & $\Delta H_{h}^{\circ}$ & $\Delta S_{h}^{\circ}$ & $\overline{\mathrm{E}_{\propto}}$ \\
\hline \multirow{4}{*}{ 0.0\% EtOH } & 293.15 & 0.047 & 7.47 & \multirow{4}{*}{9.111} & \multirow{4}{*}{-0.005} & \multirow{4}{*}{0.028} \\
\hline & 298.15 & 0.049 & 7.60 & & & \\
\hline & 303.15 & 0.051 & 7.45 & & & \\
\hline & 308.15 & 0.055 & 7.43 & & & \\
\hline \multirow{4}{*}{ 30\% EtOH } & 293.15 & 0.0041 & 13.35 & \multirow{4}{*}{26.330} & \multirow{4}{*}{-0.044} & \multirow{4}{*}{0.014} \\
\hline & 298.15 & 0.0047 & 13.24 & & & \\
\hline & 303.15 & 0.0050 & 13.00 & & & \\
\hline & 308.15 & 0.0069 & 12.74 & & & \\
\hline \multirow{4}{*}{$50 \%$ EtOH } & 293.15 & 0.0010 & 16.74 & \multirow{4}{*}{22.916} & \multirow{4}{*}{-0.021} & \multirow{4}{*}{0.024} \\
\hline & 298.15 & 0.0012 & 16.54 & & & \\
\hline & 303.15 & 0.0014 & 16.50 & & & \\
\hline & 308.15 & 0.0016 & 16.40 & & & \\
\hline \multirow{4}{*}{ 70\% EtOH } & 293.15 & 0.040 & 7.82 & \multirow{4}{*}{11.499} & \multirow{4}{*}{-0.012} & \multirow{4}{*}{0.011} \\
\hline & 298.15 & 0.043 & 7.79 & & & \\
\hline & 303.15 & 0.048 & 7.63 & & & \\
\hline & 308.15 & 0.050 & 7.62 & & & \\
\hline \multirow{4}{*}{$100 \%$ EtOH } & 293.15 & 0.031 & 8.43 & \multirow{4}{*}{465.21} & \multirow{4}{*}{-0.0205} & \multirow{4}{*}{0.001} \\
\hline & 298.15 & 0.040 & 7.98 & & & \\
\hline & 303.15 & 0.043 & 7.93 & & & \\
\hline & 308.15 & 0.049 & 7.73 & & & \\
\hline
\end{tabular}

It is worth noting that, in both techniques, ( $\mathrm{pH}$ and conductivity measurement), the solvolysis constant values are different to each other, although both of which for the same compound as shown in Figure 5.

The result showed that, in all cases, the $K_{h}$ values which derived from conductometric measurements are lower than the corresponding $K_{h}$ values from $\mathrm{pH}$ measurements (see Tables 3 and 5). This may be attributed to the higher sensitivity of conductivity technique to the change in temperature to that of $\mathrm{pH}$ technique.

\section{CONCLUSIONS}

The solvolysis process of phenyl hydrazine hydrochloride in $\mathrm{H}_{2} \mathrm{O}$ and in EtOH- $\mathrm{H}_{2} \mathrm{O}$ mixtures with different percentages of ethanol; 30\%, 50\%, 70\%, $100 \%$ at different temperature $(293.15,298.15,303.15$, and $308.15 \mathrm{~K}$ ) were studied using the conductometric and $\mathrm{pH}$ metric measurements. The results show that the solvolysis constant increase as the temperature degree increase indicating that the solvolysis process is non spontaneous endothermic process. The solvolysis constant is increase as the ethanol \% increase from 
$30 \%-100 \%$. This may be due to the higher solute-solvent interaction. In comparing the obtained values of the solvolysis constant from both the $\mathrm{pH}$ and the conductivity measurements, it was noted that the conductivity values are lower than that of $\mathrm{pH}$ values. This may be due to the higher sensitivity of conductivity measurements to the change in temperature than that of $\mathrm{pH}$ measurements.

\section{REFERENCES}

[1] Raymond Chang, J. T. J., Physical chemistry for the chemical and biological sciences. University Science Books, 2000.

[2] Freifelder, D., Study guide for Molecular biology, , 2nd ed. (A series of books in biology, Series of books in biology (Jones and Bartlett)). Boston: Jones and Bartlett, 1987, p. 834.

[3] Glasstone, S., The electrochemistry of solutions, 3rd ed. Ann Arbor, MI: Methuen and Co. Ltd., London, 2001.

[4] Rúa, J., J. Soler, F. Busto, and D. De Arriaga, "The pH Dependence and Modification by Diethyl Pyrocarbonate of Isocitrate Lyase from Phycomyces blakesleeanus," European Journal of Biochemistry. 232, 2, 381-390, 1995.

[5] Campbell, A. N. and E. Bock, "The Limiting Equivalent Conductances of Ammonium Chloride, Ammonium Bromide, and Ammonium Nitrate at $35^{\circ} \mathrm{C}$," Canadian Journal of Chemistry. 36, 2, 330-338, 1958.

[6] Tan, Z. H. et al., "Hydrogen generation via solvolysis of $\mathrm{Mg}_{2} \mathrm{Si}$," Journal of Alloys and Compounds. 770, 108-115, 2019.

[7] Fang, F., Y. Liu, F. Meng, W. Wang, T. Xue, and T. Qi, "Influence of magnesium and aluminum salts on solvolysis of titanyl sulfate solution," Transactions of Nonferrous Metals Society of China. 25, 10, 3475-3483, 2015.

[8] Barth, A. P., C. F. Tormena, and W. H. Viotto, "pH influences solvolysis of sodium polyphosphate in dairy matrices and the structure of processed cheese," Journal of Dairy Science. 100, 11, 8735-8743, 2017.

[9] Terborg, L. et al., "Ion chromatographic determination of solvolysis products of hexafluorophosphate salts in aqueous solution," Analytica Chimica Acta. 714, 121-126, 2012.

[10] Bayissa, L. D., Y. Ohmae, and M. Hojo, "Specific influence of salts on the solvolysis reaction rate of p-nitrophenyl anthranilate in binary acetonitrile-water solvents," Journal of Molecular Liquids. 199, 294-300, 2014.

[11] Li, S., D. Gan, Y. f. Zhu, Y. Liu, G. Zhang, and L. Li, "Influence of chloride salts on hydrogen generation via solvolysis of $\mathrm{MgH}_{2}$ prepared by hydriding combustion synthesis and mechanical milling," Transactions of Nonferrous Metals Society of China. 27, 3, 562-568, 2017.

[12] Safraoui, A., M. Calmon, and J.-P. Calmon, "Kinetics of the alkaline solvolysis of several alkyl phenylcarbazates," Journal of the Chemical Society, Perkin Transactions 2, 9, 1349-1352, 1991.

[13] Dong, S., M. J. Bortner, and M. Roman, "Analysis of the sulfuric acid solvolysis of wood pulp for cellulose nanocrystal production: A central composite design study," Industrial Crops and Products. 93, 76-87, 2016.

[14] Licht, S., K. Longo, D. Peramunage, and F. Forouzan, "Conductometric analysis of the second acid dissociation constant of $\mathrm{H}_{2} \mathrm{~S}$ in highly concentrated aqueous media," Journal of Electroanalytical Chemistry and Interfacial Electrochemistry. 318, 1, 111-129, 1991.

[15] Buss, J. L. and P. Ponka, "Solvolysis of pyridoxal isonicotinoyl hydrazone and its analogs," Biochimica et Biophysica Acta (BBA)-General Subjects. 1619, 2, 177-186, 2003.

[16] Kundu, A., S. Dasmandal, T. Majumdar, and A. Mahapatra, "Effect of cosolvents in the presence 
of sodium dodecyl sulfate micelles on the rate of alkaline solvolysis of tris (2,2'-bipyridine) iron(II) complex," Colloids and Surfaces A: Physicochemical and Engineering Aspects. 452, 148153, 2014.

[17] Ballance, S., K. A. Kristiansen, J. Holt, and B. E. Christensen, "Interactions of polysaccharides extracted by mild acid solvolysis from the leaves of Sphagnum papillosum with either phenylhydrazine, o-phenylenediamine and its oxidation products or collagen," Carbohydrate Polymers. 71, 4, 550-558, 2008.

[18] Karlsson, A. and S. K. Singh, "Acid solvolysis of sulphated polysaccharides. Desulphation and the effect on molecular mass," Carbohydrate Polymers. 38, 1, 7-15, 1999.

[19] El-Dossoki, F. I., N. S. Y. Abdolla, E. A. Gomaa, and O. K. Hamza, "An insight into thermodynamic and association behaviours of cocamidopropyl betaine (CAPB) surfactant in water and water-alcohol mixed media," SN Applied Sciences. 2, 4, 690, 2020.

[20] El-Dossoki, F. I., N. S. Y. Abdolla, and S. E. T. Elmasly, "The transport properties and the association behavior of some 1:1 and 2:1 electrolytes in some binary alcoholic-aqueous mixtures," Journal of Molecular Liquids. 163, 3, 135-140, 2011. 